\title{
Safe and effective canakinumab-treatment of neonatal onset multisystem inflammatory disease (NOMID)/ chronic infantile neurologic cutaneous and articular (CINCA)
}

\author{
M Tsinti, ${ }^{*}$ Dermentzoglou, E Tsitsami
}

From 8th International Congress of Familial Mediterranean Fever and Systemic Autoinflammatory Diseases Dresden, Germany. 30 September - 3 October 2015

\section{Introduction}

NOMID/CINCA is the most severe phenotype of cryopyrin-associated periodic syndrome (CAPS), characterized by persistence of inflammation-mediated symptoms and overproduction of interleukin (IL)- $1 \beta$, associated with significant morbidity, if untreated. In CAPS-patients early initiation of anti-IL1 $\beta$-treatment appears to prevent severe disease sequelae. However, canakinumab as a $1^{\text {st }}$-line treatment in young infants suffering from NOMID has been scarcely reported.

\section{Objectives}

To report the effects of early-onset canakinumab-treatment in NOMID/CINCA.

\section{Patients and methods}

Case presentation.

\section{Results}

A late-preterm (37-weeks- gestational-age) girl presented fever, urticarial-like rash, perilimbal redness, meningitis, elevation of WBC/neutrophils, ESR, CRP on 20 hours of life and severe anemia necessitating RBC-transfusion in the $5^{\text {th }}$ day of life. NOMID/CINCA was suspected on the basis of persistence of elevated inflammatory (including SAA) markers in the absence of infection-causative organisms in blood, CSF and urine, of non-responsiveness to antibiotics, of persistent CNS inflammation (CSF pleiocytosis and elevated protein) and of neutrophilic infiltration (revealed by skin biopsy) in the areas of urticarial-like rash. The detection of the c.1792A $>\mathrm{T}$ (p.Ile598Phe) mutation (de-novo as it was no detected in parents) in exon 3 of the NLRP3-gene, causative for NOMID/CINCA according to the infevers-database, confirmed the diagnosis. Brain-MRI was normal despite persistent CNSinflammation represented by pleiocytosis and elevated protein and IL-6 and IL-8-levels in CSF (lumbar puncture performed on the $1^{\text {st }}$-day and $3^{\text {rd }}$-month of life). In peripheral blood IL-1 $\beta$, IL- 6 and IL- 8 were undetectable. Opthalmoscopy/fundoscopy, and auditory-evoked-potentials were normal. After providing immunizations anti-IL1 $\beta$ treatment with canakinumab $4 \mathrm{mg} / \mathrm{kg} / 8$ weeks was initiated in the age of 4-months. Fever and rash remitted in $24 \mathrm{~h}$. Inflammatory markers normalized after 5-days. On 16-months of age the disease remains into remission. The only sign that persists is perilimbal redness. Mental and motor development is normal. No sensorineural or skeletal manifestations developed. Self-limited, 24h-duration, scarce urticarial-rash appeared in the age of 6 and 15 months with concomitant mild elevation of $\mathrm{WBC} /$ neutrophils and SAA but normal CRP and ESR levels. Repeat MRI revealed absence of CNS involvement and lumbar puncture was not repeated. No adverse reactions presented apart from 1 URI after 12-months of canakinumab treatment.

\section{Conclusion}

Early initiation of canakinumab-treatment in CINCA leads to disease-remission and appears to prevent the development severe disease-sequelae such as CNS, sensorineural and skeletal manifestations. The patient presented no severe adverse reactions. 


\section{Consent to publish}

Written informated consent for publication of their clinical details was obtained from the patient/parent/guardian/ relative of the patient.

Published: 28 September 2015

doi:10.1186/1546-0096-13-S1-P209

Cite this article as: Tsinti et al: Safe and effective canakinumabtreatment of neonatal onset multisystem inflammatory disease (NOMID)/ chronic infantile neurologic cutaneous and articular (CINCA). Pediatric Rheumatology 2015 13(Suppl 1):P209.

Submit your next manuscript to BioMed Central and take full advantage of:

- Convenient online submission

- Thorough peer review

- No space constraints or color figure charges

- Immediate publication on acceptance

- Inclusion in PubMed, CAS, Scopus and Google Scholar

- Research which is freely available for redistribution

Submit your manuscript at www.biomedcentral.com/submit 